\title{
Building a society conducive to the use of corporate social responsibility as a tool to develop disaster resilience with sustainable development as the goal: an interpretive structural modelling approach in the Indian context
}

\author{
Repaul Kanji ${ }^{1 *}$ and Rajat Agrawal ${ }^{2}$
}

\footnotetext{
* Correspondence: repaul23@gmail. com

${ }^{1}$ Gujarat Institute of Disaster Management, Behind Pandit Deendayal Petroleum University, Raisan, Gandhinagar, Gujarat 382007, India

Full list of author information is available at the end of the article
}

\begin{abstract}
The indomitable spirit of growth of mankind has led to rapid urbanisation and development, steered by industries and corporates. Whether development begets disaster or disaster begets development, is still a matter of on-going discussions and debates, but, each time the society takes a catastrophic hit, humanity begs to question the role of corporate in disaster mitigation, management and rehabilitation. The Companies Act, 2013 of India has steered India into becoming one of the few countries with a mandatory CSR regime. This study finds its genesis in the logical question that follows this premise; since expenditure through CSR is already mandatory in India and is directed towards sustainable development, why not channel such investments in such a manner that disaster resilience becomes inclusive of the final objective of sustainable development? The purpose of this study is to identify those crucial elements of our society and their inter-dependencies which when ideally tweaked and nurtured will lead to a social setup where CSR investments would lead to sustainable development inclusive of disaster resilience.

Extensive literature followed by questionnaire survey and interviews were used as a tool to judge and evaluate societal enablers and then they were subjected to interpretive structural modelling which brought out the contextual relationships among the enablers. The resultant model is a hierarchical structure of enablers, revealing their interdependencies and relations with each-other. This can help enterprises, corporates, policymakers to understand how to leverage the mandatory CSR regime of India in their favour as well as to create disaster resilience.
\end{abstract}

Keywords: Corporate social responsibility, interpretive structural modelling, disaster resilience and risk reduction

\section{Background}

The concept of Corporate Social Responsibility (CSR) has always been a matter of discussion, be it formally or informally, officially or unofficially and this has been so since the 1950s. Archie Carroll, one of the most influential academician in this field of study

(c) The Author(s). 2019 Open Access This article is distributed under the terms of the Creative Commons Attribution 4.0 International License (http://creativecommons.org/licenses/by/4.0/), which permits unrestricted use, distribution, and reproduction in any medium, provided you give appropriate credit to the original author(s) and the source, provide a link to the Creative Commons license, and indicate if changes were made. 
suggests that the volume of work by Howard R. Bowen published in 1953 as Social Responsibilities of the Businessman marks the beginning of modern day literature in this field. The basic idea behind Bowen's work is that businesses are "vital centres of power and decision making and that the actions of these firms touches the lives of citizens at many points", thus, "what responsibilities to society may businessman reasonably be expected to assume?" This statement, in particular, holds true even today. Down the ages, businesses have expanded, enterprises have grown, processes have become more and more complex owing to globalisation and this in turn has demanded a lot from the societies, primarily in the form of human resources and natural resources. It is in this context that the question posed by Bowen becomes much more relevant, that, are these businesses and enterprises pursuing policies or following those lines of action "which are desirable in terms of the objectives and values of our society"?

In a world dominated by the tremendous urge of multidimensional growth, development in the form of urbanisation leading to globalisation is obvious. This development and growth is steered by industries, corporations etc. and often, they are the expense of resources; natural and human. The global ecosystem of development has favoured the growth of such enterprises down the years and not only have the business processes become hazardous (oil refineries, steel plants etc.), they are also found to have encroached on lands which are vulnerable (hydro-power projects in hilly terrain prone to earthquake and landslides). As these businesses increase in number, a whole range of problems arise and multiply along with it like emission of greenhouse gases, global warming, climate change to name a few. In turn, they lead to extreme events like flash-flood, cyclones, frequent recurrence of extreme episodes and either affect the business, not only the ones mentioned above but also others, directly, or affects its supply chain. Thus, beyond any iota of doubt, enterprises, corporations, businesses are affected by disasters; the society they cater to is affected and since businesses are an integral part of the society, it is also upon them to ensure that they take care of themselves as well as the society.

The involvement of private sector in disaster management, relief and rehabilitation is hardly three decades old. The United Nations International Decade for Natural Disaster Reduction (1989 - 1999) "maintained consistently that the primary responsibility for disaster reduction rests with national governments, but recognised the need for collaborative efforts between governments, UN agencies and other actors of all kinds." Resolution 44/ 236, in fact, encouraged the national governments to mobilise necessary support from public and private sectors. Berke and Wenger (1991) pointed out that private sector companies are well staffed and equipped to handle disaster response and recovery activities and encouraged their involvement on the ground. Many international forum's on CSR have propounded greater CSR involvement in mitigation, thereby, paving the path of involvement in pre-disaster phases of disaster management. However, evidences show that this practise has not yet taken up. Twigg in his study (2001) has cited example of 38 initiatives that involves multi-lateral cooperation between corporates and NGOs. Of these, 10 initiatives are global in nature, only 9 are in developing countries and the remaining are in developed countries. Surprisingly enough, only the Philippines feature in the list among South Asian countries. Examples from countries like Sri Lanka and Bangladesh reveal that CSR in disaster management is still lurking in the phases of relief, rehabilitation or purely one-off philanthropic endeavours. 
A study conducted by Matin (2002), points out that in Bangladesh "during major disaster times, the Prime Minister in a drive to collect relief funds personally receives donations from people. The event is ceremonial and often televised. This in turn provides further encouragement to such public donations." It also cites another example; during the floods of 1998, the President of Bangladesh Garment Manufacturers and Exporters Association (BGMEA) visited the affected areas and distributed $3700 \mathrm{kgs}$ of flour, 3700 kgs of molasses, 11017 packets of oral rehydration solution and 3700 leafs of water purifying tablets and paracetamol tablets. Even in India such examples are replete. Rajib Shaw in his article titled "The Corporate Sector Role in Disaster and Environmental Management" (2005), correctly pointed out that CSR activities are found to be either one-off type of intervention or focussed on post-disaster activities or an initiative that does not involve the local community. Thus, the primary need of the hour is to curb the above trend and emphasise on preparedness, mitigation and resilience rather than just relief and rehabilitation. An example of such initiatives is the FICCI-CARE that came into being after the Gujrat earthquake of 2001, which intended to not only rehabilitate but also build resilience in the affected communities. United Nations Office for Disaster Risk Reduction defines resilience as "the ability of a system, community or society exposed to hazards to resist, absorb, accommodate, adapt to, transform and recover from the effects of a hazard in a timely and efficient manner, including through the preservation and restoration of its essential basic structures and functions through risk management."

The Sendai Framework for Disaster Risk Reduction (2015-2030) talks about enforcing the shift of paradigm from disaster management to disaster risk management and disaster risk reduction. Even the Sustainable Development Goals encompass the same ideology. Thus, leveraging the mandatory CSR regime of India to foster disaster resilience and sustainable development will be an appropriate step. But the question remains; is the socio-political ecosystem of India ready to facilitate the transition of CSR investments from mere relief and rehabilitation to preparedness or disaster resilience in general? Section 135 of the Companies Act, 2013, implemented in India, reads, "Every company having net worth of rupees five hundred crore or more, or turnover of rupees one thousand crore or more or a net profit of rupees five crore or more during any financial year shall..[spend] in every financial year, at least two per cent. of the average net profits of the company made during the three immediately preceding financial years, in pursuance of its Corporate Social Responsibility Policy." This is, indeed, a one of a kind initiative and India is the first and the only country to have made CSR expenditure mandatory and it might appear that this legislation is indeed a good way to develop resilience, but, inherent within, are barriers like,

a. Failure to identify disaster resilience as an apt avenue of CSR investment; relief and rehabilitation appears to be more attractive prospect for businesses to become visible rather than silently investing in strategies designed towards disaster resilience.

b. Skewed investments in a particular sector; there are certain avenues or sectors like education or health and hygiene, which attracts more investment from different companies due to varied reasons like ease of investment (minimum strategising required) or simply because investment in such avenues, which are already aligned to government plans and schemes, will give political mileage and more publicity. 
For the last 2 years, education and health has remained the most favoured sectors of investment and hardly two percentage of the total CSR investments of all the eligible companies have gone in disaster management and that too primarily in disaster relief and rehabilitation.

Thus, even before we intend to create disaster resilience through corporate social responsibility, the need of the hour is to:

a. Understand the dynamics between different parameters that exists in our society, so that they can be tapped and tweaked to facilitate the development of an ecosystem where CSR investments will no longer be a one-time event or channeled only into a few favoured sector but a harmonised effort towards sustainable development.

b. Align the avenues of investment of CSR funds in such a way that the ultimate objective will be sustainable development but disaster resilience would be implicitly imbibed within the bigger objective.

This particular study will focus on the first need; identification of parameters, henceforth to be called enablers, and their dynamics, so that they can be tapped, tweaked and exploited to initiate the development of a favourable ecosystem.

The second point will form the basis of future studies as very less work has been done in India in this particular area of incorporating the ideology of disaster resilience with sustainable development and achieving it through investments out of CSR funds.

This study focusses on,

1. Identifying the enablers or drivers which can lead to the development of a society where CSR can be used as an effective tool to attain the Sustainable Development Goals (SDGs) with disaster resilience as an incorporated target.

2. Modelling these enablers and their contextual relationships, depicting order and direction on the complexity of relationships amongst various elements, based on primacy, priority, and, cause and effect using the interpretive structural modelling (ISM) (Warfield 1976; Gorvett 2006; Sahney et al. 2010), followed by a detailed MICMAC analysis of the multi-hierarchical model.

\section{Literature review and enabler identification}

In alignment with the focus of the study, the idea was to identify unique enablers of the society in the Indian context which would trigger the development of an ecosystem where CSR would be used as a tool of development and disaster resilience. The mandatory CSR regime instituted by the Government of India was the first big step in this direction. But, the investments through CSR funds, henceforth, were skewed and lacked the holistic outlook as envisaged by the government. The question that logically follows is how to orient the investments towards sustainable development? A first hand research into the issue revealed that there are a number of factors that play a very important role in this regard; corporates invest in avenues to have a better public visibility, they invest in avenues which are aligned with government schemes and plans to earn political mileage, corporates invest in avenues where less strategising is required (health and hygiene, for example; distributing medical supplies to the hospitals in the area they 
are operating) and in some cases, the lack of public pressure to coerce the corporate to contribute to the society in a meaningful way. So, on the face of it, it appeared that all the involved stakeholders have a role to play in building the desired ecosystem; the corporates need to have a holistic approach of their CSR investments and they also need a prospect of interest to lure them into spending in the attainment of sustainable development goals and disaster resilience, the political will, policies and frameworks must also be oriented in that fashion and the civil society, too, needs to be aware of their necessities and the responsibilities due to them.

Based on this initial understanding, efforts were made to go through all the available material (literature, articles, news reporting etc.) and identify enablers as well as barriers to get a whole picture of the scenario as it exists, in the Indian context. A thorough study of all relevant documents like research papers, draft articles, white papers, news reporting, details of which are discussed along with each identified enabler, led to the realisation that certain enablers, which academicians thought can be used to advantage, were common and repeatedly appeared in more than one document while some were unique and represented only a particular scenario. Attempt was made to extrapolate all such enablers to the Indian scenario. The following section contains the enablers that were identified, their sources and how they have been perceived and interpreted in this study. It is to be noted that all the identified enablers have been evaluated from three perspectives:

a. From the perspective of the corporate: Why should we invest? What is our benefit?

b. From the perspective of legislators, policy-makers: What can be done to promote the interest of corporates to invest in SDG and disaster resilience?

c. From the perspective of the society: What responsibilities are due to us and how do we ensure that we are benefitted with what is necessary?

\section{Awareness (E1)}

Source

A Government document titled "Disaster Risk Management and the Role of Corporate Sector" by the Ministry of Home Affairs, India, emphasises on "involvement of corporate sector in awareness generation and disaster preparedness and mitigation planning through sensitisation, training and co-opting of the corporate sector and their nodal bodies in planning process and response mechanisms". The document although highlights the need of corporates to pull up their socks and indulge in spreading awareness about vulnerabilities through informative booklets on hazards associated with their processes and the steps to be taken for preparedness and mitigation. The same document mentioned above and a manual prepared by Public-Private Partnerships for Disaster Management Initiative in China (2008), focusses on mock dills and "limited mobilisation of resources (e.g. personnel, equipment, etc.) used to simulate and test response plans, often focused on one component of the plan (e.g. building evacuation).

\section{Understanding}

Technically speaking, awareness is a two-way street. Awareness is not only about the community knowing about the persistent vulnerabilities and their right to claim the 
operating corporate's responsibility towards them, but it is also about the employees working in the corporate knowing about the risks they are surrounded with, evacuation routes, evacuation plans, role of each personnel as per as the disaster management plan of the enterprise. Apart from this serious awareness, employees should also be aware of the fact that CSR is almost a right of the community and it is in no way a distribution of sympathy and philanthropy.

\section{Interpretation}

Such a sort of culture amongst the employees, makes CSR all the more effective tool of holistic development and to top that, if the awareness amongst the beneficiaries can inculcate awareness among professionals, personnels and employees, CSR initiatives and its impact would grow in leaps and bounds. Thus, awareness is an enabler which needs to be worked upon to ensure disaster resilience and off course, sustainability of the enterprise as well as the immediate community around it.

\section{Proactive attitude (E2)}

Source

"Corporate Social Responsibility \& Disaster Reduction: An Indian Overview" by SEEDS, India (2002) is an authoritative document in this field. This document talks about the level of pro-activeness or readiness that should be inculcated within the corporates by stating that "one disaster team in the company should be ready all time to tackle any kind of disaster" and they address the issue of lack of interest on the part of district administration by fostering the need to educate the administration about disaster management plans and efforts. "The Corporate Sector Role in Disaster and Environmental Management: Beyond Corporate Social Responsibility", a white paper prepared by the Global Forum for Disaster Reduction (GFDR) and Graduate School of Global Environment Studies, Kyoto University, emphasises "without properly taking actions that is proactive...., the level of impact of disaster and environmental hazards will be much more worse."

\section{Understanding}

Rather than response and short-term measures, proactive attitude is what is the need of the hour. Since few years there have been many vocal supporters of the fact that disaster management as an approach needs a paradigm shift and eventually it is undergoing such a change: from "relief only" it is moving to preparedness i.e. from management it is moving towards mitigation. Companies are also required to move in the same manner towards holistic development rather than 'help in need' attitude. Such evidences of paradigm shift are rare but not non-existent.

\section{Interpretation}

Proactive attitude is considered as an enabler because it is expected to play an integral role in fostering the shift from response to preparedness. If the government, through its policies, declare incentives for industries and enterprises to be pro-active, i.e., use their CSR funds to design and implement disaster management and disaster risk reduction plans for its immediate community, it will lead to the development of a resilient 
community. On the other hand, if the policy-makers are pro-active in nature, they will ensure that disaster risk reduction is mainstreamed into development plans and agendas. In fact, such steps are being actively taken in many South Asia countries.

Location and nature of the company (E3)

Source

The SEEDS document, mentioned above, illustrates that population accumulation in hazard zones due to better facilities, amenities and accessibilities have brought migrant labour resulting in unplanned settlements in zones prone to storm-surge and similar high-risk zones. It also puts forth the idea of "risks of disasters getting compounded due to industry's presence (e.g. in the aftermath of the Orissa Super cyclone, 1999, an industrial chemical tank in Paradip was on the verge of exploding due to its cooling systems having been made inoperative by power failure. Generators had to be flown in to avert a second disaster.)"

\section{Understanding}

The location of the company plays an important role while deciding the CSR initiatives of the company. Couple with this factor, the operational hazards of the company decisively puts a moral bearing on the company towards fulfilling its social responsibilities.

\section{Interpretation}

CSR initiatives should be determined by the location of the company but it is not the case. To understand the importance, let us consider an example of an enterprise, the establishment of which required deforestation. Due to strict environmental policies, afforestation in the ratio of 1:3 ( 1 tree cut to be replaced by 3 new ones) is done, but in a different area altogether. This is against the scope of sustainable development and the lack of afforestation, perhaps, may lead to landslides. If the immediate community residing around that enterprise is affected by such a landslide, all residents who are also employees will be affected and this in turn will affect the enterprise. Thus, CSR strategies and initiatives should be holistic in approach and the location of the enterprise should be a determining factor. To facilitate this, a pro-active local government may enforce a legislation to ensure that the enterprise takes its location and the immediate community in account while designing its CSR strategies.

\section{Brand and reputation (E4)}

\section{Source}

Corporate sustainability: Drivers and enablers, prepared by KPMG and FICCI in India Sustainability Conclave 2014, talks about "corporate identity" being a key instrument in strategising sustainable action plans; the increased reporting of CSR and sustainability issues has led to the big corporates leveraging the media space to enjoy enhanced brand image and intense reputation surge.

\section{Understanding}

The procedure of reporting the CSR initiatives of a company in accordance to the internationally accepted standards, which is also a requirement of the Companies Act 
(2013), works as a positive pressure for a company as the CSR initiatives are brought to the limelight and the company enjoys fame and popularity. This results in "a positive image of the company in the eye of the public and the employees' morale is boosted, which in turn has a positive effect on the productivity of the company", states a report on CSR and natural disaster reduction in Sri Lanka (2002).

\section{Interpretation}

Thus, it goes without any figment of doubt that CSR endeavours specially in times of dire need (disasters, epidemics etc.) appeals to the sympathetic threads of humanity which makes the company more acceptable to the society and it enjoys quantum leap in areas like investment, expansion, diversification etc.

\section{Business opportunities in social investments (E5)}

Source

A National Institute of Disaster Management (NIDM), New Delhi, document takes note of the fact that the increased conundrum of climate change, sustainable goals have opened up new avenues of business investments and opportunities. GIS based risk assessment and mapping by integrating spatial data collected through satellite or field surveys, early warning systems of earthquake or tsunami, disaster communications through HAM, retrofitting of buildings and structures in high seismic zones are some of the few lucrative fields in which one can now invest foreseeing the future trends of development. Vinod Kumar Duggal, member of the National Disaster Management Authority (NDMA), identifies other avenues where corporate sector can opt to play a crucial role by enforcing a techno-legal regime which gives away facilities, incentives only if certain standards are met. He also emphasised on the need of cost-effective, innovative technologies for disaster management.

\section{Understanding}

In tune with the above information, government schemes like Startup India and Standup India, can function with excellent synergy. Such schemes are like incentives to modern day technologists who are now being encouraged to develop low-cost, efficient technologies for disaster management; initiatives like Skill India can work to develop skills which are particularly useful during disasters.

\section{Source}

Barbieri et al. (2010) puts forth the idea of eco-efficient innovations. They define such innovations as those "which reduce the material and energy amounts per unit produced, eliminate toxic substances and increase product's life cycle."

\section{Interpretation}

The existing big shot corporates can employ or seed-fund these upcoming firms as a part of their CSR endeavour which would serve dual purpose; it will help the new firms get clients and the existing corporates to invest in promoting social entrepreneurship. In a job-starved country, promoting employment through such strategies ensures development and financial resilience in times of disaster. Another way of harvesting such 
an opportunity is by creating a market by initially making a social investment. SC Johnson nurtured the habit and culture of clean toilets through CSR initiatives in Kenya. The move saw tremendous change and huge development in habits of the residents. Once clean toilets became a habit and a necessity, SC Johnson withdrew the CSR initiative as Kenya had already become a willing market of their toilet cleaning and sanitation products. Thus, they taught the world how CSR can effectively bring about social change and also create market space.

\section{National regulations and international compliances (E6)}

Source

"Corporate Social Responsibility and Disaster Reduction: A Global Overview" by John Twigg (2001), states that at national, international and even at local levels, collective initiatives by business organisations or dedicated organisations play a very important role. The Yokohama strategy (1994) called for "integration of the private sector in disaster reduction efforts through promotion of business opportunities". The Hyogo Framework for action 2005-2015, strongly proposes the role of corporates in reducing disaster risks of communities. The Kyoto Protocol, one of the most celebrated multilateral agreements signed in the context of climate change, patronises instruments like Clean Development Mechanism to ensure involvement of a developed nation. The most recent amongst all this, the Paris Agreement doubly emphasises on common but differentiated responsibilities.

\section{Understanding}

As an international player, India is a party to many such international agreements and frameworks. Thus, there is a constant peer pressure to abide by such clauses and India has done impeccably well in living up to the expectations of the international powers without compromising on any national needs. The submission of Intended Nationally Determined Contribution (INDC) in lieu with the climate change agreements also reflects the willingness of India to contribute to the cause. The more India, as a nation, contributes, the more social pressure would build up on the companies to abide by provisions like CDM which invariably enforces environment sustainability, eco-friendly processes leading to disaster resilience. Examples of similar sorts are also available.

\section{Interpretation}

Commitment of India as a nation to such international frameworks and agreements and the political and bureaucratic intent to abide by such regulation would impact the national regulations and in turn would affect the activities of enterprises and even their associations. Thus, if proper international frameworks are in place and they are adhered to nationally, it may be expected that even CSR initiatives would no more be one-off affairs.

\section{Awards, recognition and incentives (E7)}

Source

The development of sustainability index by the Bombay Stock Exchange and the Indian Institute of Corporate Affairs is a remarkable step to provide recognition for CSR 
initiatives. Dr. R. K. Dave, Senior specialist (Policies and Plans), National Disaster Management Authority, India in his concept paper on CSR in Disaster Risk Reduction supports the idea of incentives for disaster risk reduction initiatives taken within the ambit of CSR. However, there is also a catch. Christine Bader, an independent researcher, in an article titled "The Bangladesh factory collapse: Why CSR is more important than ever?" points out that there are issues of perverse incentives. There are cases where companies or individuals are awarded for efficiently and effectively handling a major disaster begging the question 'why was there a disaster at all? what about those who made sure that such a disaster never happens?'

\section{Understanding}

The recent trend of awarding companies depending on their CSR performance has gained huge audience in India. Various trusts, various organisations, various confederations are recognising the efforts put in by companies in CSR initiatives. These awards go down into the annual reports and websites of the company and act as an excellent instrument to gain popularity, publicity, strategic business advantages like investments.

\section{Interpretation}

The growing trend of recognition, be it through different platforms, has become a driving force to perform better in CSR initiatives and as awareness among people is growing towards sustainability, environment friendliness, the entire process is wheeling towards disaster resilience.

\section{Legislation (E8)}

Source

Compliance of an enterprise, be it private or public, to Section 135 of the Companies Act (2013), has created a regime of mandatory CSR expenditure of "at least $2 \%$ of the average net profits of the company made during the three immediately preceding financial years", if the company has "net worth of INR 500 crore or more; or turnover of INR 1000 crore or more; or net profit of INR 5 crore or more during any financial year".

\section{Understanding}

A detailed study of the illustrative but not exhaustive list of the activities which would be counted as CSR investment reveals that as on one hand where there is emphasis on women empowerment, upliftment of backward classes etc., on the other hand, there are avenues listed which directly or indirectly builds the capacity of the society like ensuring environmental sustainability, maintenance of ecological balance, contribution to Prime Minister's Relief Fund etc.

\section{Interpretation}

The basic legislation required to facilitate the use of CSR as a tool of development is already in place. This particular enabler already has a positive impact, however, the way it is implemented in will determine the success or outcome. 


\section{Ease of doing CSR (E9) \\ Source}

While the corporate sector and the Government representatives nod to the need of partnership with NGOs and each other, in reality they are reluctant to give away the power of decision making. (Corporate Social Responsibility \& Disaster Reduction, SEEDS, 2002). It has also been discussed amongst leading experts that corporates are suspicious of NGOs thinking that they might take the whole credit and NGOs feel that corporates should have a 'cash only' relationship with them, giving away the decision making power to the NGOs in a particular joint venture. Another aspect of ease of doing CSR is the issue of red-tapes and improper liaisons during post-disaster strategies of relief and rescue which forces the CSR committees to be biased towards opting the option of contributing in Prime Minister's Relief Fund which would save them the tiring effort of associating themselves with any relief activity.

\section{Understanding}

Ease of doing CSR, contextually focusses on the ease with which organisations, enterprises and government liaise with each other based on mutual trust and worth and less of bureaucratic hurdles.

\section{Interpretation}

More the ease to coordinate and liaise, irrespective of the domain of the organisation, better are the chances of the CSR strategies being implemented in a correct manner.

\section{Vision (E10)}

\section{Source}

The Sustainability Conclave Report (2014) of Federation of Indian Chambers of Commerce and Industry (FICCI) points out that "Sustainability vision is a function of the company's history, affiliations, regional policy scenario and sectoral maturity in the context of its long-term growth strategy."

\section{Understanding}

The relevance of this particular parameter lies in the fact that if the vision of the company encompasses service towards the society as one of its prime intention then in due course of time, the vision parameter manifests itself in the company's strategy and hence in its organisation structure and governance which inherently then reflects themes like social performance, social responsibility and sustainability and in such a scenario, the CSR strategies would also reflect the same.

\section{Interpretation}

Vision is an effective enabler because it can truly inspire the activities of an enterprise. Especially for those companies which are legally not bound to fulfil their CSR, vision of the company can instigate the company to indulge in CSR, going above and beyond of what is legally expected from them. 
Religion and culture (E11)

Source

Madhavi Malalgoda Ariyabandu and Preethi Hulangamuwa in their research paper titled "Corporate Social Responsibility and Natural Disaster Reduction in Sri Lanka" state that "the concept of acquiring merit in a spiritual sense was a main motivator of their action (disaster relief through CSR)"

\section{Understanding}

Buddhism, Hinduism, Islam, Christianity are few of the religions that are followed in India and religion has always been a sentimental aspect for Indians. It has been noted that in the relief activities conducted by the private sector, many companies are more willing to work with religious institutions rather than governmental agencies or NGOs in their efforts. Institutes like Ramkrishna Mission, Bharat Sevashram Sangha are few of those religious institutes with whom corporates and NGOs join hands during relief and rehabilitation. Thus religious motivation can work wonders when it comes to CSR, social help and holistic development. This is a perfect example of how collective conscience can drive social development. Hofstede 1980, identified four primary dimensions of culture which eventually grew into six; power distance index, collectivism or individualism, masculinity or femininity, uncertainty avoidance index, long-term orientation or short term orientation and restraint or indulgence. Out of these, the research focusses on collectivism which emphasises on "we" rather than on "I". Collectivism promotes undoubted loyalty and support for each other when a conflict arises. Thus, if a culture is inclined towards collectivism it would assuredly lead to better plans, better operations, better legislations and also improved efficiency. Another important dimension is the uncertainty avoidance index. A society with high index value would invariably believe in rigid codes, guidelines i.e. it would want to be well prepared for any mishap. This particular aspect or dimension fosters the previously discussed idea of pro-activeness and it also shapes up the culture of "being ready".

\section{Interpretation}

Given the context of India, religion and culture is a parameter which can either be used as an enabler or as an impediment. The relationship of this parameter with the other parameters outlined till now will determine the direction in which it can be used.

\section{Political influence (E12)}

Discussions with personnel from few different enterprises and a survey amongst academicians gave a subtle understanding that selection of CSR projects to be implemented is sometimes guided by political influence.

\section{Source}

\section{Understanding}

It would not be incorrect to assume that if the political leader of a region encompasses disaster mitigation, disaster resilience and risk reduction in his plans of development, 
then his influence over CSR initiatives can become an effective enabler in a particular region.

\section{Interpretation}

This enabler is very objective in nature as it inherently depends upon the social designs, political stature and character of the leader.

Few other enablers were also identified along with these like "Trend of training", "Design of a disaster management plan", "Active role of confederations", "Willingness and involvement of employees", "Cost effective technologies for disaster management" but they were done away with by merging their core concept with one of the above enablers after discussion with the experts. Enablers like "Trend of training", "Design of a disaster management plan" were merged with "Awareness", "Legislation" and "National regulations and international compliances" as it is only through proper awareness, legal and societal pressures like framework and law of the land such enablers like training and disaster management plans manifest themselves. Similarly, "Willingness and involvement of employees" was merged with "Vision" and "Cost effective technologies for disaster management" was merged with "Business opportunities in social investment".

\section{Methodology}

\section{Validation of Enablers}

After shortlisting the enablers, it was important to check their relevance and that was the very first step into further analysis. In order to have a balanced mix of respondents, the survey was targeted towards academicians (teaching and students), enterprise personnel associated with decision making boards or committees, and few general respondents to understand how the identified enablers are perceived by a common man. The survey was based on a 5-point Likert scale (1 being enabler not influencing disaster resilience and 5 being enabler influencing disaster resilience). Cronbach's Coefficient $(\alpha)$, which reflects the internal consistency was calculated to be 0.738 . Table 1 shows the mean score of the enablers based on which they have been ranked.

Pearson's bivariate two-tailed correlation was performed to check whether any multi co-linearity exists. The correlation coefficients have been tabulated in Table 2 . The enablers have been abbreviated E1 to E12 for quick reference (abbreviated based on their ranks).

ISM is one of the best ways to give defined shapes to "poorly articulated mental models".(Sage 1977; Warfield 1982). This technique helps to establish relationships among a set of variables which could be directly or indirectly related, to establish a hierarchical structure for better understanding of a complicated decision making environment. As commented by Sushil (2012), ISM technique is probably one of the most handy technique to identify structure within the system. Sahney et al. 2010 points out that ISM was developed by Warfield and it "ultimately leads to a portrayal of the direct and indirect relationships among the various elements in a system, through a multi-level structural model.

Experts from the concerned field were invited to develop relationship among the enablers. 20 experts were approached and briefed in advance before the final discussions with a draft paper that explained the enablers and how they have been perceived in this 
Table 1 Rank of the enablers

\begin{tabular}{llll}
\hline Sl. No & Enabler & Mean Score & Ranking \\
\hline E1 & Awareness & 4.5 & 1 \\
E2 & Proactive attitude & 4.4 & 2 \\
E3 & Location and nature of the business & 4.3 & 3 \\
E4 & Brand and reputation & 4.2 & 4 \\
E5 & Business opportunities in social investment & 4.2 & 5 \\
E6 & National regulations and international compliances & 4.1 & 6 \\
E7 & Awards, recognitions and incentives & 4.0 & 7 \\
E8 & Legislation & 3.9 & 8 \\
E9 & Ease of doing CSR & 3.8 & 9 \\
E10 & Vision & 3.7 & 10 \\
E11 & Religion and culture & 3.7 & 11 \\
E12 & Political influence & 3.2 & 12 \\
\hline
\end{tabular}

study so as to give them ample amount of time to understand how the enablers were selected and how they can be related to each other. This is the first step in the modelling; Sahney (2010) says that "the process begins with the identification of elements that could be related to each other in a system. Direct and indirect relationships are then identified between these elements, which are then converted into a matrix that is finally structured into a model through a hierarchical configuration." These experts included academicians as well as corporate personnel who are well aware of the context of CSR and disaster management.

\section{Analysis}

The finalised enablers, E1 to E12, is subjected to analysis using ISM Technique. The technique comprises of various steps which finally leads to the development of a multi-hierarchy model of digraph.

Table 2 Correlation coefficient of enablers

\begin{tabular}{|c|c|c|c|c|c|c|c|c|c|c|c|c|}
\hline & E8 & E10 & E3 & E4 & E9 & E6 & E7 & E5 & E2 & E11 & E1 & E12 \\
\hline E8 & 1.000 & & & & & & & & & & & \\
\hline E10 & -0.057 & 1.000 & & & & & & & & & & \\
\hline E3 & -0.004 & 0.714 & 1.000 & & & & & & & & & \\
\hline E4 & 0.057 & -0.227 & -0.077 & 1.000 & & & & & & & & \\
\hline E9 & -0.263 & 0.168 & 0.198 & 0.721 & 1.000 & & & & & & & \\
\hline E6 & 0.520 & 0.000 & 0.350 & 0.595 & 0.495 & 1.000 & & & & & & \\
\hline E7 & 0.209 & 0.102 & 0.437 & 0.417 & 0.412 & 0.535 & 1.000 & & & & & \\
\hline E5 & 0.028 & 0.000 & 0.188 & 0.429 & 0.422 & 0.203 & 0.475 & 1.000 & & & & \\
\hline E2 & 0.092 & 0.060 & 0.328 & 0.612 & 0.493 & 0.624 & 0.730 & 0.495 & 1.000 & & & \\
\hline E11 & -0.453 & 0.242 & 0.318 & 0.035 & 0.254 & -0.063 & -0.237 & 0.042 & -0.018 & 1.000 & & \\
\hline E1 & 0.306 & 0.259 & 0.610 & 0.282 & 0.209 & 0.565 & 0.423 & 0.257 & 0.469 & -0.020 & 1.000 & \\
\hline E12 & -0.096 & 0.000 & 0.241 & -0.096 & -0.128 & -0.221 & 0.052 & 0.288 & -0.161 & 0.459 & -0.000 & 1.000 \\
\hline
\end{tabular}




\section{Step 1: Formation of Structural Self-Interaction Matrix (SSIM)}

The experts consulted, concluded upon relationships among the identified enablers which are laid down in SSIM following the given rules,

- V: enabler $\mathrm{i}$ affects enabler $\mathrm{j}$

- A: enabler $\mathrm{j}$ affects enabler $\mathrm{i}$

- X: enabler $\mathrm{i}$ and enabler $\mathrm{j}$ affects each other

- O: enabler $i$ and enabler $j$ does not affect each other.

Where, the value for $\mathrm{i}$ are the enablers numbered from 1 to 12 .

Table 3 is the SSIM, which is used for further analysis.

The following interpretations would elaborate and illustrate how the matrix was developed.

i. E12 ( Religion and culture) influences E1 (Awareness): As discussed earlier, the culture of a society and the nation as a whole determines the nature of the people. If they belong to society with high uncertainty avoidance index, then it is obvious that they would be interested in keeping themselves aware and hence prepared for any situation.

ii. E1 (Awareness) and E10 (Vision) has no influence on each other in any way. In this regard, it is required that awareness and vision is understood in the particular way that the study has perceived them to be.

iii. E1 (Awareness) affects E2 (Proactive attitude): The more aware the people are, the more aware the administration is, more proactive would be the governmental development schemes, more positive pressure would be felt by both the government and the corporates to engage in capacity building exercises.

iv. E8 (Legislation) and E12 (Religion and culture) affect each other: The culture of a society or a nation, for that matter, influences the nature of legislation, rules, laws and in turn the legislations i.e. regulations play a crucial role in shaping up the culture. Practises like Sati, which many believed to be a part of our culture (debatable), were abolished and banned thereby refining the culture. Thus, these enablers affect each other.

Table 3 Structural Self-Interaction Matrix

\begin{tabular}{|c|c|c|c|c|c|c|c|c|c|c|c|c|}
\hline & E12 & E11 & E10 & E9 & E8 & E7 & E6 & E5 & E4 & E3 & E2 & $\overline{E 1}$ \\
\hline$\overline{E 1}$ & V & 0 & 0 & 0 & $A$ & 0 & 0 & $A$ & 0 & $A$ & $A$ & \\
\hline E2 & V & A & 0 & $A$ & A & O & A & V & 0 & A & & \\
\hline E3 & 0 & 0 & 0 & 0 & A & 0 & A & V & 0 & & & \\
\hline E4 & A & 0 & O & 0 & 0 & A & $A$ & V & & & & \\
\hline E5 & A & 0 & 0 & 0 & A & A & 0 & & & & & \\
\hline E6 & A & A & A & V & A & V & & & & & & \\
\hline E7 & A & 0 & 0 & 0 & A & & & & & & & \\
\hline E8 & $x$ & A & 0 & V & & & & & & & & \\
\hline E9 & A & A & 0 & & & & & & & & & \\
\hline E10 & 0 & A & & & & & & & & & & \\
\hline E11 & V & & & & & & & & & & & \\
\hline E12 & & & & & & & & & & & & \\
\hline
\end{tabular}




\section{Step 2: Initial Reachability Matrix (IRM)}

From Table 3, the Initial Reachability Matrix (IRM), which is a binary matrix, is prepared using the rules put forth by Jharkharia and Shankar (2004), Harland et al. (2007). The rules can be summed up as follows:

- $V$ in $(i, j)$ in $\operatorname{SSIM}$ corresponds to $(i, j)=1$ and $(j, i)=0$ in IRM.

- $A$ in $(i, j)$ in SSIM corresponds to $(i, j)=0$ and $(j, i)=1$ in IRM.

- $X$ in $(i, j)$ in SSIM corresponds to $(i, j)=1$ and $(j, i)=1$ in IRM.

- $O$ in $(i, j)$ in SSIM corresponds to $(i, j)=0$ and $(j, i)=0$ in IRM (Table 4).

Once the Initial Reachability Matrix is developed, it is using this matrix that the Final Reachability Matrix is developed. The Final Reachability Matrix id constructed using the simple logic of transitivity. If an enabler A is reachable from enabler B (B to A) and an enabler $C$ is reachable from enabler $A$ ( $A$ to $C$ ), then enabler $C$ is reachable from enabler B ( $\mathrm{B}$ to $\mathrm{C}$ ) and the values in the Final Reachability Matrix is updated accordingly. Table 5 is constructed using the above mentioned logic.

Table 5 is used to calculate, for each enabler, the driving power and dependence of each enabler. The row summation of each enabler gives the driving power of that enabler i.e. the number of other enablers it drives while the column summation of every enabler gives the dependency of each enabler i.e. the number of other enablers it depends upon. The calculation of driving power (DP) and dependence is illustrated in Table 6.

\section{Step 3: Partitioning the enablers at appropriate levels using iteration}

The reachability set $(R)$ and antecedent set $(C)$ for each enabler is calculated from Table 5 ; the reachability set of any enabler is composed of all those enablers which are reachable from that particular enabler and the antecedent set is composed of all those enablers on which the enabler in consideration is dependent upon. The intersection set of these sets i.e., $(\mathrm{R} \cap \mathrm{C})$ is obtained for each enabler and thus starts the first iteration. Whenever the reachability set and the intersection set are the same for an enabler, that particular enabler is removed from the iteration table along with members of the intersection set and the

Table 4 Initial Reachability Matrix

\begin{tabular}{lllllllllllll}
\hline & E1 & E2 & E3 & E4 & E5 & E6 & E7 & E8 & E9 & E10 & E11 & E12 \\
\hline E1 & 1 & 0 & 0 & 0 & 0 & 0 & 0 & 0 & 0 & 0 & 0 & 1 \\
E2 & 1 & 1 & 0 & 0 & 1 & 0 & 0 & 0 & 0 & 0 & 0 & 1 \\
E3 & 1 & 1 & 1 & 0 & 1 & 0 & 0 & 0 & 0 & 0 & 0 & 0 \\
E4 & 0 & 0 & 0 & 1 & 1 & 0 & 0 & 0 & 0 & 0 & 0 & 0 \\
E5 & 1 & 0 & 0 & 0 & 1 & 0 & 0 & 0 & 0 & 0 & 0 & 0 \\
E6 & 0 & 1 & 1 & 1 & 0 & 1 & 1 & 0 & 1 & 0 & 0 & 0 \\
E7 & 0 & 0 & 0 & 1 & 1 & 0 & 1 & 0 & 0 & 0 & 0 & 0 \\
E8 & 1 & 1 & 1 & 0 & 1 & 1 & 1 & 1 & 1 & 0 & 0 & 1 \\
E9 & 0 & 1 & 0 & 0 & 0 & 0 & 0 & 0 & 1 & 0 & 0 & 0 \\
E10 & 0 & 0 & 0 & 0 & 0 & 1 & 0 & 0 & 0 & 1 & 0 & 0 \\
E11 & 0 & 1 & 0 & 0 & 0 & 1 & 0 & 1 & 1 & 1 & 1 & 1 \\
E12 & 0 & 0 & 0 & 1 & 1 & 1 & 1 & 1 & 1 & 0 & 0 & 1 \\
\hline
\end{tabular}


Table 5 Final Reachability Matrix

\begin{tabular}{lllllllllllll}
\hline & E1 & E2 & E3 & E4 & E5 & E6 & E7 & E8 & E9 & E10 & E11 & E12 \\
\hline E1 & 1 & 0 & 0 & $\mathbf{1}$ & $\mathbf{1}$ & $\mathbf{1}$ & $\mathbf{1}$ & $\mathbf{1}$ & $\mathbf{1}$ & 0 & 0 & 1 \\
E2 & 1 & 1 & 0 & $\mathbf{1}$ & 1 & $\mathbf{1}$ & $\mathbf{1}$ & $\mathbf{1}$ & $\mathbf{1}$ & 0 & 0 & 1 \\
E3 & 1 & 1 & 1 & 0 & 1 & 0 & 0 & 0 & 0 & 0 & 0 & $\mathbf{1}$ \\
E4 & $\mathbf{1}$ & 0 & 0 & 1 & 1 & 0 & 0 & 0 & 0 & 0 & 0 & 0 \\
E5 & 1 & 0 & 0 & 0 & 1 & 0 & 0 & 0 & 0 & 0 & 0 & $\mathbf{1}$ \\
E6 & $\mathbf{1}$ & 1 & 1 & 1 & $\mathbf{1}$ & 1 & 1 & 0 & 1 & 0 & 0 & $\mathbf{1}$ \\
E7 & $\mathbf{1}$ & 0 & 0 & 1 & 1 & 0 & 1 & 0 & 0 & 0 & 0 & 0 \\
E8 & 1 & 1 & 1 & $\mathbf{1}$ & 1 & 1 & 1 & 1 & 1 & 0 & 0 & 1 \\
E9 & $\mathbf{1}$ & 1 & 0 & 0 & $\mathbf{1}$ & 0 & 0 & 0 & 1 & 0 & 0 & $\mathbf{1}$ \\
E10 & 0 & $\mathbf{1}$ & $\mathbf{1}$ & $\mathbf{1}$ & 0 & 1 & $\mathbf{1}$ & 0 & $\mathbf{1}$ & 1 & 0 & 0 \\
E11 & $\mathbf{1}$ & 1 & $\mathbf{1}$ & $\mathbf{1}$ & $\mathbf{1}$ & 1 & $\mathbf{1}$ & 1 & 1 & 1 & 1 & 1 \\
E12 & $\mathbf{1}$ & $\mathbf{1}$ & $\mathbf{1}$ & 1 & 1 & 1 & 1 & 1 & 1 & 0 & 0 & 1 \\
\hline
\end{tabular}

Bold fonts are relevant as they represent the changes that occurs in table according to the logics stated in the different steps

process is repeated. The enabler thus removed would occupy top level in the model. The enablers which finds their place at the top of the model, i.e., if an enabler is eliminated before another, the former would not affect or influence the later enabler in anyway. This repetitive iteration builds a hierarchy with enablers at different levels (Table 7).

\section{Step 4:Constructing Digraph or Driving Power-dependence diagram}

Figure 1 depicts the directed graph (digraph) obtained from Table 6 and they have been clustered into four coordinates.

- Autonomous enablers (I): Enablers with weak driving power and weak dependence. E3.

- Dependent enablers (II): Enablers with weak driving power but strong dependence. E4, E5, E7, E9.

Table 6 Driving power and Dependence of enablers

\begin{tabular}{llllllllllllll}
\hline & $E 1$ & $E 2$ & $E 3$ & $E 4$ & $E 5$ & $E 6$ & $E 7$ & $E 8$ & $E 9$ & $E 10$ & $E 11$ & $E 12$ & DP \\
\hline E1 & 1 & 0 & 0 & 1 & 1 & 1 & 1 & 1 & 1 & 0 & 0 & 1 & $\mathbf{8}$ \\
E2 & 1 & 1 & 0 & 1 & 1 & 1 & 1 & 1 & 1 & 0 & 0 & 1 & $\mathbf{9}$ \\
E3 & 1 & 1 & 1 & 0 & 1 & 0 & 0 & 0 & 0 & 0 & 0 & 1 & $\mathbf{5}$ \\
E4 & 1 & 0 & 0 & 1 & 1 & 0 & 0 & 0 & 0 & 0 & 0 & 0 & $\mathbf{3}$ \\
E5 & 1 & 0 & 0 & 0 & 1 & 0 & 0 & 0 & 0 & 0 & 0 & 1 & $\mathbf{3}$ \\
E6 & 1 & 1 & 1 & 1 & 1 & 1 & 1 & 0 & 1 & 0 & 0 & 1 & $\mathbf{9}$ \\
E7 & 1 & 0 & 0 & 1 & 1 & 0 & 1 & 0 & 0 & 0 & 0 & 0 & $\mathbf{4}$ \\
E8 & 1 & 1 & 1 & 1 & 1 & 1 & 1 & 1 & 1 & 0 & 0 & 1 & $\mathbf{1 0}$ \\
E9 & 1 & 1 & 0 & 0 & 1 & 0 & 0 & 0 & 1 & 0 & 0 & 1 & $\mathbf{5}$ \\
E10 & 0 & 1 & 1 & 1 & 0 & 1 & 1 & 0 & 1 & 1 & 0 & 0 & $\mathbf{7}$ \\
E11 & 1 & 1 & 1 & 1 & 1 & 1 & 1 & 1 & 1 & 1 & 1 & 1 & $\mathbf{1 2}$ \\
E12 & 1 & 1 & 1 & 1 & 1 & 1 & 1 & 1 & 1 & 0 & 0 & 1 & $\mathbf{1 0}$ \\
Dependence & $\mathbf{1 1}$ & $\mathbf{8}$ & $\mathbf{6}$ & $\mathbf{9}$ & $\mathbf{1 1}$ & $\mathbf{7}$ & $\mathbf{8}$ & $\mathbf{5}$ & $\mathbf{8}$ & $\mathbf{2}$ & $\mathbf{1}$ & $\mathbf{9}$ & $\mathbf{8 5}$ \\
\hline
\end{tabular}


Table 7 Iteration table

\begin{tabular}{|c|c|c|c|c|}
\hline Level & & Reachability Set & Antecedent Set & Intersection Set \\
\hline \multicolumn{5}{|c|}{ 1st Iteration } \\
\hline & E1 & 145678912 & 1234567891112 & 145678912 \\
\hline & E2 & 1245678912 & 236891012 & 26812 \\
\hline & E3 & 123512 & 368101112 & 312 \\
\hline I & E4 & 145 & 124678101112 & 145 \\
\hline \multirow[t]{8}{*}{ । } & E5 & 1512 & 1234567891112 & 1512 \\
\hline & E6 & 1234567912 & 1268101112 & 12612 \\
\hline & E7 & 1457 & 12678101112 & 17 \\
\hline & E8 & 12345678912 & 1281112 & 12812 \\
\hline & E9 & 125912 & 12689101112 & 12912 \\
\hline & E10 & 23467910 & 1011 & 10 \\
\hline & E11 & 123456789101112 & 11 & 11 \\
\hline & E12 & 12345678912 & 12356891112 & 1235689 \\
\hline \multicolumn{5}{|c|}{ 2nd Iteration } \\
\hline & E1 & 689 & 23678911 & 689 \\
\hline & E2 & 26789 & 236891011 & 2689 \\
\hline & E3 & 23 & 3681011 & 3 \\
\hline & E6 & 23679 & 2681011 & 26 \\
\hline \multirow[t]{2}{*}{$\|$} & E7 & 7 & 26781011 & 7 \\
\hline & E8 & 236789 & 2811 & 28 \\
\hline \multirow[t]{4}{*}{$\|$} & E9 & 29 & 26891011 & 29 \\
\hline & E10 & 2367910 & 1011 & 10 \\
\hline & E11 & 2367891011 & 11 & 11 \\
\hline & E12 & 236789 & 2368911 & 23689 \\
\hline \multicolumn{5}{|c|}{ 3rd Iteration } \\
\hline & E1 & 68 & 36811 & 68 \\
\hline & E2 & 68 & 3681011 & 68 \\
\hline \multirow[t]{6}{*}{ III } & E3 & 3 & 3681011 & 3 \\
\hline & E6 & 36 & 681011 & 6 \\
\hline & E8 & 368 & 811 & 8 \\
\hline & E10 & 3610 & 1011 & 10 \\
\hline & E11 & 3681011 & 11 & 11 \\
\hline & E12 & 368 & 36811 & 368 \\
\hline \multicolumn{5}{|c|}{ 4th Iteration } \\
\hline & E1 & 68 & 6811 & 68 \\
\hline & E2 & 68 & 681011 & 68 \\
\hline \multirow[t]{5}{*}{ IV } & E6 & 6 & 681011 & 6 \\
\hline & E8 & 68 & 811 & 8 \\
\hline & E10 & 610 & 1011 & 10 \\
\hline & E11 & 681011 & 11 & 11 \\
\hline & E12 & 68 & 6811 & 68 \\
\hline \multicolumn{5}{|c|}{ 5th Iteration } \\
\hline V & E1 & 8 & 811 & 8 \\
\hline V & E2 & 8 & 81011 & 8 \\
\hline
\end{tabular}


Table 7 Iteration table (Continued)

\begin{tabular}{lllll}
\hline Level & & Reachability Set & Antecedent Set & Intersection Set \\
\hline$V$ & E8 & $\mathbf{8}$ & $\mathbf{8 1 1}$ & $\mathbf{8}$ \\
$V$ & E10 & $\mathbf{1 0}$ & $\mathbf{1 0} \mathbf{1 1}$ & $\mathbf{1 0}$ \\
& E11 & 81011 & 11 & 11 \\
$V$ & E12 & $\mathbf{8}$ & $\mathbf{8 1 1}$ & $\mathbf{8}$ \\
6th Iteration & & & $\mathbf{1 1}$ \\
VI & E11 & $\mathbf{1 1}$ &
\end{tabular}

- Linkage enablers (III): Enablers with strong driving power and strong dependence. E1, E2, E6, E12.

- Independent enablers (IV): Enablers with strong driving power and weak dependence. E8, E10, E11.

Step 5:

On the basis of the iterations, the enablers are arranged in different hierarchy levels in accordance to the relationships obtained in Table 3. Figure 2 illustrates the hierarchical relationship of the enablers.

\section{Results}

\section{MICMAC Analysis}

Understanding and analysing the driving power of each enabler and their dependence on each other is what MICMAC analysis is all about. (Barve et al. 2007 ; Mandal and Deshmukh 1994 ). Bringing forth the results obtained in Step 4 of ISM Analysis, the enablers are grouped into four clusters.

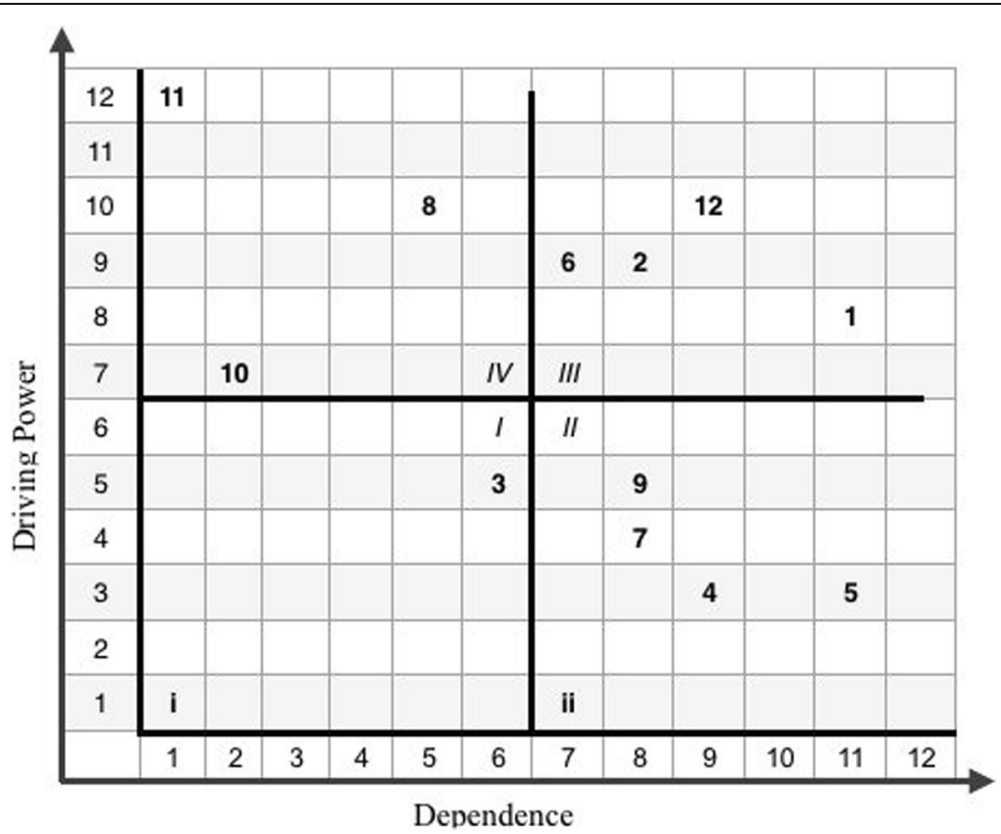

Fig. 1 Driving power and dependence graph 


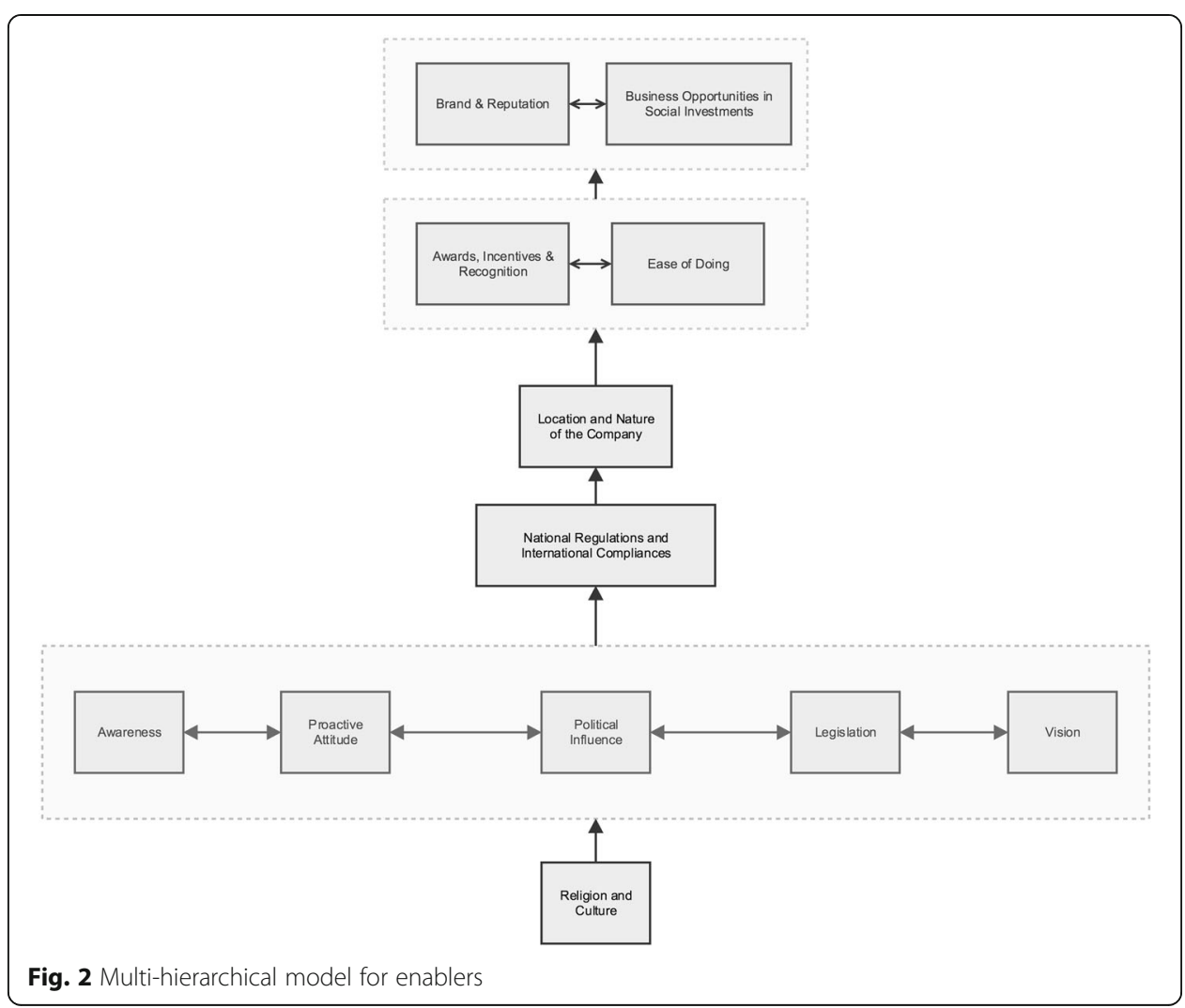

The first cluster of autonomous enablers (weak driving power and weak dependence) consists of "Location and nature of the company" only. This shows that the location and the nature of the company hardly has any influence on any other parameter that has been considered and is also very weakly dependent on other parameters. Religion and culture, vision etc. should not determine the nature and location, however, international rules and national legislations may affect it, thus, the weak dependence. Location and nature of the company may weakly affect the ease of doing CSR. For example, when there is an association of companies working on similar processes, they generally tend to focus on similar kind of CSR activities as well and sometimes it becomes easy for them because one just needs to follow the footsteps of others; it is very usual to see motorcycle companies investing in spreading awareness about wearing helmets during riding, driving responsibly etc.

The cluster of dependent enablers (weak driving power but strong dependence) is composed of "Business opportunities in social investments", "Brand and reputation", "Award, recognition and incentives", and "Ease of doing CSR". These factors become an efficient enabler only when they are backed by other positive enablers. For example, brand and reputation or awards and recognitions would be an inspiring factor for the companies to invest in disaster resilience through CSR only if there is an ecosystem where these things are recognised by the society. Moreover, in order to receive awards, recognitions, a company has to follow certain rules and regulations and once they achieve recognition through awards, their brand and reputation enjoys a formidable rise. It is only through incentives provided by government or any such authorities that a company would be interested in investing socially towards a business opportunity. Thus, these enablers are dependent on other enabler for their fulfilment and they can only complement the entire process but not lead it. 
The third cluster of linkage enablers (strong driving power and strong dependence) like "Awareness", "Proactive attitude", "National regulations and international compliances" and "Religion and culture". Awareness is achieved through education, knowledge, culture and it is awareness that can lead to social pressure which ensures maximum result in case of CSR like activities. Similar is the case with proactive attitude; until and unless people are aware and have a culture that supports readiness and preparedness, people, government, societies will not be proactive and it is through stringent pro-activeness that CSR can be leveraged for the holistic development of the society.

The final cluster of independent enablers (strong driving power and weak dependence) consists of "Legislation", "Vision" and "Political influence". Legislation of a country depends upon the religious influences and the overall cultural backdrop and same is the case with vision of a company which depends upon the cultural and religious beliefs and economic goals of the founder. Thus, it has very less dependency but these are enablers which directly or indirectly facilitates all other enablers. In a country like India, or any developing country for that matter, political influence plays a huge role in every aspect of life and it demands no discussion and debate. Thus, logical interpretations of the analysis gives a fair amount of idea of how these enablers are influenced or influence the entire process which can spearhead the idea of using CSR as a tool.

\section{Conclusion}

\section{Discussion}

The multilevel hierarchy of enablers yields a very interesting interpretation. It should be re-iterated that the primary objective is to develop disaster resilience through CSR leveraging the mandatory CSR regime and since the path to do so is paved with hurdles like skewed investments and hefty investments in a favoured sector, this study intends to identify elements in the socio-political structure of India, which when tweaked or nurtured or re-modelled in a certain way can actually create disaster resilience and preparedness. It has already been explained how each of the identified parameters contribute towards disaster resilience, but now, using the resultant model, it is to be understood how the enablers are linked to each other and how they can finally contribute towards disaster resilience.

For the sake of understanding how the relationships work and how they all can facilitate the building of a disaster resilient society, let us assume an ideal society like Utopia.

The religion of the people and the culture of their civilisation and belief system manifests itself in the attitude of the people i.e. according to Hofstede (1980), they are either uncertainty loving people or prepared people; they either believe in individualism or they trust in groups and collectivism; they are either a masculine culture or a feminine culture and so on and so forth. Suppose, they are all things positive in the above discussion and hence they are proactive and their legislations are also an extension of their cultural character; they promote laws and regulations that brings about accountability and hence responsibility, transparency and hence mandatory disclosure of their activities, moving towards sustainability in a holistic manner. A man in this society decides to start a business thus the vision of his company would be driven and moulded in accordance to his beliefs and teachings 
which are, off course, a part of his culture. Legislations, proactive attitude inculcates awareness and if such a aware person turns out to be a political leader, his plans of development would, beyond doubt, encompass capacity building, disaster resilience i.e. holistic development. The legislations, the culture, the attitude of the people gives shape to the national regulations and discussion and debates amongst similar societies gives rise to international agreements which individual states willingly abide by. This hypothetical setup referred as Utopia in our discussion is the manifestation of idealism, where debates and discussions leads to agreement and not adjournment. Local laws, national regulations, international compliances guide the location of a new business and the processes its should follow. If such a business abides by the regulations and compliances it receives awards and recognition and when it supports the government to achieve a national goal, it receives incentives. These incentives drive the company to invest in avenues which are a not a part of their primary business but are social investments; companies strive to identify business opportunities in social investments. Moreover, when a company receives incentives and is recognised nationally, the aspect of distrust during outsourcing and liaison do not appear; companies explore other possible and probable ways of joining hands seamlessly during disasters, mishaps and catastrophes. Even the law of the land, in such case, smoothens the feared prospect of inter-agency cooperation during emergencies. Thus, this is how each of the identified enablers would lead an efficient use of CSR as an incredible tool develop a society of which disaster resilience is a part.

The following section illustrates how the different enablers can possibly be used in the real context.

Legislation is an enabler which can be modified and influenced; strict implementations and penalties are few ways of doing it and it will automatically influence the other enablers it is linked to. Legislation driven national regulations can be used to introduce rules like mandatory and dedicated CSR, if location and process poses a threat to the immediate society. This, to some extent, will curtail the issue of investment in favoured sectors. The practice of engaging in CSR in a distant area, just for the sake of engaging in CSR, without paying any heed to the harms being caused in the immediate society, is one such ill practice that can be eradicated through this step.

Awareness can be spread using various techniques and it is one of the primary enablers that can lead to the effective use of CSR. Awareness of the company will lead to investment in proper avenues and awareness of the society will force the company to invest in the necessary avenues. Awareness of the society, which expresses itself as 'local demands' can create political pressures for sustainable development.

Incentives should be introduced by the government to encourage companies in social investments, support social ventures and finding cost-effective solutions to disaster risk reduction and sustainable development.

In terms of ease of investing in CSR in disaster resilience, legislations and frameworks, both national and international, should facilitate ease of liaising during emergencies with minimum red-tapes and bureaucratic hurdles. The Nepal earthquake saw such problems and it is the least expected during relief and rehabilitation work. 
Brand, reputation and business opportunities are the immediate attractions that draws a company towards investing in CSR. Thus, it is this element that should be exploited by policymakers to interest corporates and enterprises to invest in CSR in a proper way.

\section{Understanding the limitation of the study}

It is important to note that the enablers identified and analysed in this study are somewhat the silver lining, for in real life only few of them function in the way it is supposed to; it needs to be understood that out of the identified enablers only few can be manipulated or modified but not all.

For example, religion and culture of a nation or a society can not be changed or altered but it can be used to advantage by leveraging the humanitarian side of it. To illustrate this point, one might fall back to the study of Sharma and Talwar (2005), where the authors quote that in Vedic economic approach, welfare happens to be the primary concern. In case of a Hindu enterprise, if this very statement becomes the economic pillar of the vision of the enterprise, it is obvious that there CSR strategies would encompass holistic development. The authors go explaining that "Bhagwad Gita says universe is an undivided whole" and since since every particle is connected with every other particle, "doing well to others ultimately does well to the doer", but the corporate world has forgotten to take care of this aspect off late. Every other religion echoes a similar sentiment and if one imbibes the true essence of it, CSR will no longer be concentrated in few favoured sector and it will almost automatically lead to sustainable and holistic development.

\section{Research implications and future scope}

The study reveals few interesting aspects of CSR, which can be extrapolated to the context of CSR in general and not only to CSR in disaster resilience.

The obtained model conforms to what Weber had proposed way back that religious values have impact on and in workplaces (1905). In India, even though its manifestation, particularly in business, might not be obvious but this research shows that culture and religion is perhaps the most motivating and powerful enabler that directly or indirectly lurks behind every other reason, even in business. Secondly, the immediate enablers or the immediate reasons for a company to invest in CSR activities are business opportunity, fame, reputation and heightened brand value. Thus, these avenues should be explored in a meaningful way by pro-active policy-makers to ensure that CSR investments are channeled into holistic development. And finally, this research work establishes a firm ground to promote a future line of inquiry; can a scale or a tool be developed which can be used by the corporate houses to measure the impact of their CSR strategies from the perspective of sustainable development and disaster resilience?

The very idea of the research was to identify all enablers and propagate the idea of how all these enablers are associated and linked with each other so that appropriate authorities be it the government or the corporates can develop and nurture the drivers which would eventually lead to a resilient society but before that create a society where CSR can be used as a tool to achieve the same; CSR will no longer remain a one-off intervention but will become an agent of change and development. 


\section{Abbreviations}

CDM: Clean Development Mechanism; CSR: Corporate social responsibility; FICCI: Federation of Indian Chambers of Commerce and Industry; GFDR: Global Forum for Disaster Reduction; IDRN: India Disaster Resource Network; INDC: Intended Nationally Determined Contribution; IOCL: Indian Oil Corporation Limited; IRM: Initial Reachability Matrix; ISM: Interpretive structural modelling; NDMA: National Disaster Management Authority of India; NGO: Non Governmental Organisations; NIDM: National Institute of Disaster Management; SDG: Sustainable Development Goals; SFDRR: Sendai Framework for Disaster Risk Reduction (2015 - 2030); SSIM: Structural Self Interaction Matrix

\section{Acknowledgements}

We are thankful to the group of experts from various organisation and institutes to contribute to our study and helping us to come to a decisive conclusion which can be used in so many different ways by different sections of people in the society.

\section{Funding}

No funding was received for the study that has been mentioned in the article

\section{Availability of data and materials}

The data on which the modelling is based on will be made available on contacting the corresponding author of the article.

\section{Authors' contribution}

RK is the primary author responsible for the collection of data and subsequent modelling while the RA is responsible for introducing the idea of using ISM as an approach to identify the contextual relationship amongst various enablers. The final drafting of the manuscript was done by both the authors. Both authors read and approve the final manuscript.

\section{Competing interests}

There are no competing interests to the best of the authors' knowledge.

\section{Publisher's Note}

Springer Nature remains neutral with regard to jurisdictional claims in published maps and institutional affiliations.

\section{Author details}

${ }^{1}$ Gujarat Institute of Disaster Management, Behind Pandit Deendayal Petroleum University, Raisan, Gandhinagar, Gujarat 382007, India. ${ }^{2}$ Department of Management Studies, Indian Institute of Technology Roorkee, Roorkee, India.

Received: 8 February 2018 Accepted: 11 April 2019

Published online: 14 May 2019

\section{References}

Ariyabandu M, Hulangamuwa P (2002) Corporate social responsibility and natural disaster reduction in Sri Lanka. ITDG-South Asia, Colombo Retrieved from https://assets.publishing.service.gov.uk/media/57a08d32e5274a31e00016de/ R7893Privatesectorstudy.pdf.

Barbieri J, de Vasconcelos I, Andreassi T, de Vasconcelos F (2010) Innovation and sustainability: New models and propositions. Revista De Administração De Empresas 50(2). https://doi.org/10.1590/S0034-75902010000200002

Barve A, Kanda A, Shankar R (2007) Analysis of interaction among the barriers of Third Party Logistics. IJASM 2(1):109. https:// doi.org/10.1504/ijasm.2007.015684

Benfield Greig Hazard Research Centre (2001) Corporate Social Responsibility and Disaster Reduction: A Global Overview, London Retrieved from https://assets.publishing.service.gov.uk/media/57a08d66ed915d3cfd0019e8/R7893CSROverview. pdf.

Berke P, Wenger D (1991) Linking Hurricane Disaster Recovery to Sustainable Development Strategies: St. Kitts and Nevis, West Indies (College of Architecture, Texas A7M University)

Corporate Engagement in Disaster Preparedness, Response and Recovery. (2008) (1st ed.). Retrieved from http://www. chinacsrmap.org/Uploads/\%7B98C8875E-6F8A-4293-B96D-6094F59196FB\%7D_Disaster_Management_Manual_TAF.pdf

Corporate Social Responsibility As A Response to Disaster Risk Reduction. (2016). NGO Pulse. Retrieved 30 June 2016, from http://www.ngopulse.org/article/corporate-social-responsibility-response-disaster-risk-reduction

Gorvett R (2006) Interpretive structural modeling of interactive risks. In: Paper presented at Call paper program, enterprise risk management symposium, Chicago, IL

Hofstede G (1980) Culture's consequences. Sage Publications, Beverly Hills

Hofstede G (1991) Cultures and organizations. McGraw-Hill, London

KPMG, FICCI,. (2014). Corporate sustainability: drivers and enablers. Retrieved from http://ficci.in/spdocument/20361/FICCI Sustainability_Conclave_Report2014_final.pdf.

Kytle B, Ruggie J (2005) Corporate Social Responsibility as Risk management: A Model forMultinationals. In: Working paper no 10 for corporate social responsibility initiative Retrieved from https://ipfs.io/ipfs/ QmXoypizjW3WknFiJnKLwHCnL72vedxjQkDDP1mXWo6uco/wiki/Corporate_social_responsibility.html.

Mandal A, Deshmukh S (1994) Vendor Selection Using Interpretive Structural Modelling (ISM). Int Jrnl Of Op \& Prod Mnagemnt 14(6):52-59. https://doi.org/10.1108/01443579410062086

Mani V, Agrawal R, Sharma V (2015) Impediments to Social Sustainability Adoption in the Supply Chain: An ISM and MICMAC Analysis in Indian Manufacturing Industries. Glob J Flex Syst Manag 17(2):135-156. https://doi.org/10.1007/s40171-015-0106-0

Matin N (2002) Corporate Social Responsibility and Natural Disaster Reduction: Insights from Bangladesh 
Ministry of Home Affairs, Govt. of India Disaster Risk Management and The Role of Corporate Sector. Confederation of Indian Industry, Delhi Retrieved from http://www.undp.org/content/dam/india/img/disaster_risk_manage_and_the_role_of_ corporate_sec_india_perspective.pdf

Nath V, Kumar R, Agrawal R, Gautam A, Sharma V (2013) Consumer Adoption of Green Products: Modeling the Enablers. Glob Bus Rev 14(3):453-470. https://doi.org/10.1177/0972150913496864

Sage A (1977) Interpretive structural modeling: Methodology for large scale systems. McGraw-Hill, New York, pp 91-164

Sahney S, Banwet D, Karunes S (2010) Quality framework in education through application of interpretive structural modeling. The TQM Journal 22(1):56-71. https://doi.org/10.1108/17542731011009621

SEEDS India,. (2002). Corporate Social Responsibility \& Disaster Reduction: An Indian Overview. Retrieved from http://r4d.dfid gov.uk/PDF/Outputs/Mis_SPC/R7893CSRIndia.pdf

Sharma A, Talwar B (2005) Corporate social responsibility: modern vis-à-vis Vedic approach. Meas Bus Excell 9(1):35-45. https://doi.org/10.1108/13683040510588828

Sushil (2012) Interpreting the Interpretive Structural Model. Glob J Flex Syst Manag 13(2):87-106. https://doi.org/10.1007/ s40171-012-0008-3

The Bangladesh factory collapse: why CSR is more important than ever. (2013). The Guardian. Retrieved 30 June 2016, from https://www.theguardian.com/sustainable-business/blog/bangladesh-factory-collapse-csr-important

Twigg J (2001) Corporate Social Responsibility and Disaster Reduction: A global overview. Aon Benfield UCL Hazard Centre, London

Warfield J (1976) Societal Systems. New Your. Wiley, NY

Warfield J (1982) Group Planning and Problem-Solving Methods in Engineering. Wiley, New York, pp 155-201

\section{Submit your manuscript to a SpringerOpen ${ }^{\circ}$} journal and benefit from:

- Convenient online submission

- Rigorous peer review

- Open access: articles freely available online

High visibility within the field

- Retaining the copyright to your article

Submit your next manuscript at $\boldsymbol{\sim}$ springeropen.com 